\title{
SCANNING ELASTIC LIDAR OBSERVATIONS OF AEROSOL TRANSPORT IN NEW YORK CITY
}

\author{
Adrian Diaz*, Victor Dominguez, Selma Dobryansky, Yonghua Wu, Mark Arend, Daniela Viviana \\ Vladutescu, Barry Gross, Fred Moshary
}

\author{
NOAA CREST Center and City College of New York, New York, NY 10031, USA, \\ *adiaz001@citymail.cuny.edu
}

\begin{abstract}
In this study, spatial distribution of aerosols in New York City is observed using a scanning eyesafe $532 \mathrm{~nm}$ elastic-backscatter micro-pulse lidar system. Observations show dynamics of the boundary layer and inhomogeneous distribution and transport of aerosols. The data acquired are complemented with simultaneous measurements of particulate matter and wind speed and direction. Furthermore, the system observations are validated by comparing them with a colocated multi-wavelength lidar.
\end{abstract}

\section{INTRODUCTION}

Lidar imaging of the spatial distribution of aerosols can shed light on atmospheric dynamics, aerosol transport and particulate pollution. Due to the harmful effects pollution has on human health, it is of special interest to study the aerosol distribution within the boundary layer of highly populated urban areas like New York City. Currently, there are ground-based lidars that measure vertical distribution of aerosols above New York City. However, vertically pointing instruments are unable to obtain multidimensional views of the atmosphere, hence scanning lidars are needed instead.

Previous implementations of scanning lidars at other locations have combined transmitter sources in different regions of the spectrum with different lidar techniques, some of them include elastic-backscatter lidar in the UV [1], differential absorption lidar in the IR [2] and Raman-shifted and polarization lidar in the IR $[3,4]$. The requirements for a scanning lidar are rapid scan and moderate range. These can be achieved with a high pulse energy transmitter that would allow for moderate range measurements with reduced averaging time. Nevertheless, these tend not to be eye-safe and their operation must follow strict guidelines set forth by the US
Federal Aviation Administration, and American National Standards for Safe Use of Lasers Outdoors [5].

On the other hand, micro-pulse lidars (MPL) meet the necessary eye-safety requirement for scanning and are simple and low cost. The idea of a MPL was developed by NASA in 1992 as a result of technological improvements on solid states devices accomplished at the time. It consists of a transmitter source with pulse energy in the order of micro Joules and a repetition rate of thousands of Hertz. When appropriately expanded, the energy transmitted by this source becomes eye-safe at all ranges. Moreover, the receiver employs a compact avalanche photo diode (APD) detector for effective photon counting acquisition [6]. Currently, MPL's most known use is in the NASA Micro-Pulse Lidar Network (MPLNET), which continuously measures aerosol and cloud vertical structure, as well as boundary layer heights from multiple sites around the world [7].

In this study, a commercial scanning eye-safe MPL is used to measure multi-dimensional distributions of aerosols in New York City. These measurements, combined with simultaneous measurements of particulate matter and wind speed and direction, provide information necessary to understand boundary layer dynamics and aerosol transport.

\section{METHODOLOGY}

The instrument used, the Mini-MPL, is a scanning eye-safe elastic-backscatter MPL located at the City College of New York (CCNY) and manufactured by Sigma Space with the specifications shown on table 1 .

Spatial distributions of aerosols were measured in New York City by scanning along the elevation (or polar) angle while pointing towards Bronx and Manhattan, respectively at $73^{\circ}$ and $173^{\circ}$ 
azimuth angles measured with respect to the north (figure 1). The scans consisted of sweeps from $0^{\circ}$ to $90^{\circ}$ elevation angles with $1^{\circ}$ or $2^{\circ}$ increments. At every angle, measurements were taken with 15 seconds average and $75 \mathrm{~m}$ range resolution. Using these scanning parameters, two-dimensional cross-sections were obtained with sufficient SNR within the first $5 \mathrm{~km}$ horizontally and up to $3 \mathrm{~km}$ vertically.

Table 1 Mini-MPL specifications.

\begin{tabular}{|l|l|}
\hline \multicolumn{2}{|l|}{ Transmitter } \\
\hline Wavelength & $532 \mathrm{~nm}$ \\
\hline Repetition rate & $2500 \mathrm{~Hz}$ \\
\hline Pulse Energy & $4 \mu \mathrm{J}$ \\
\hline Receiver \\
\hline Diameter & $8 \mathrm{~cm}$ \\
\hline Field of view & $220 \mu \mathrm{rad}$ \\
\hline Detector & APD photon counting \\
\hline Range resolution & $5 / 15 / 30 / 75 \mathrm{~m}$ \\
\hline
\end{tabular}

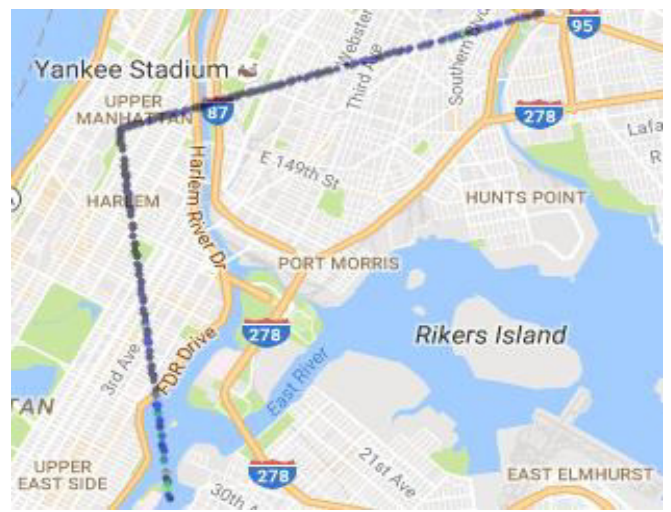

Figure 1 Map showing the directions of the scans.

\section{RESULTS}

Multiple scans were carried out during afternoon hours on July $28^{\text {th }} 2016$ (figure 2). Measurements from the first two scans show a few clouds (depicted in red). Moreover, an increase in the overall amount of aerosols can be observed throughout the day.

A co-located air monitoring station managed by the New York State Department of Environmental Conservation includes a continuous fine particulate matter (PM 2.5) sampler. It uses a $1405 \mathrm{TEOM}^{\mathrm{TM}}$ to provide hourly PM 2.5 surface concentration measurements. Data retrieved from this station shows an initial low concentration followed by a considerable increase towards the end of the day (figure 3). This is in agreement with the overall amount of aerosols observed from the scanning measurements.

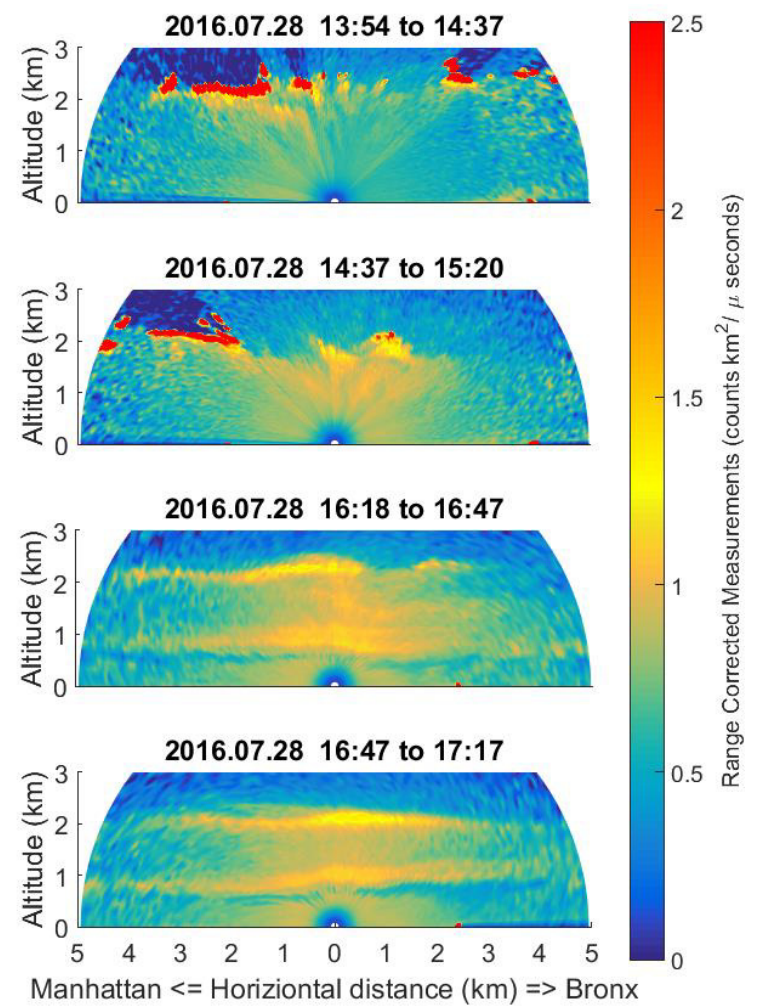

Figure 2 Aerosol distributions in New York City at different times on July $28^{\text {th }} 2016$.

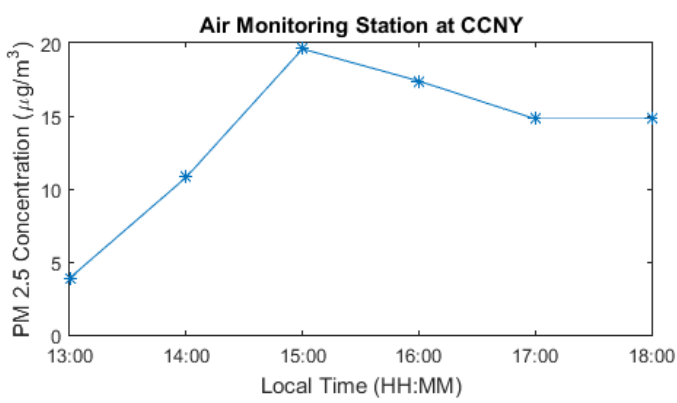

Figure 3 PM 2.5 concentration measurements from an air monitoring station at CCNY.

The last two scans show two aerosol layers at 2 $\mathrm{km}$ and between $700 \mathrm{~m}$ and $1.2 \mathrm{~km}$. It appears that the aerosol layers move to the north from Manhattan to Bronx. To further investigate this, measurements of wind speed and direction at three different locations were retrieved from the NYCMetNet network. One of them includes a 
radar wind profiler (Scintec LAP3000) reporting winds up to $2 \mathrm{~km}$ height and is located in Jersey City approx. $15 \mathrm{~km}$ from CCNY (figure 4). The other two weather stations report surface winds and are located at Yankee Stadium and Central Park West approx. 2 and $4.5 \mathrm{~km}$ from CCNY, respectively (figure 5).

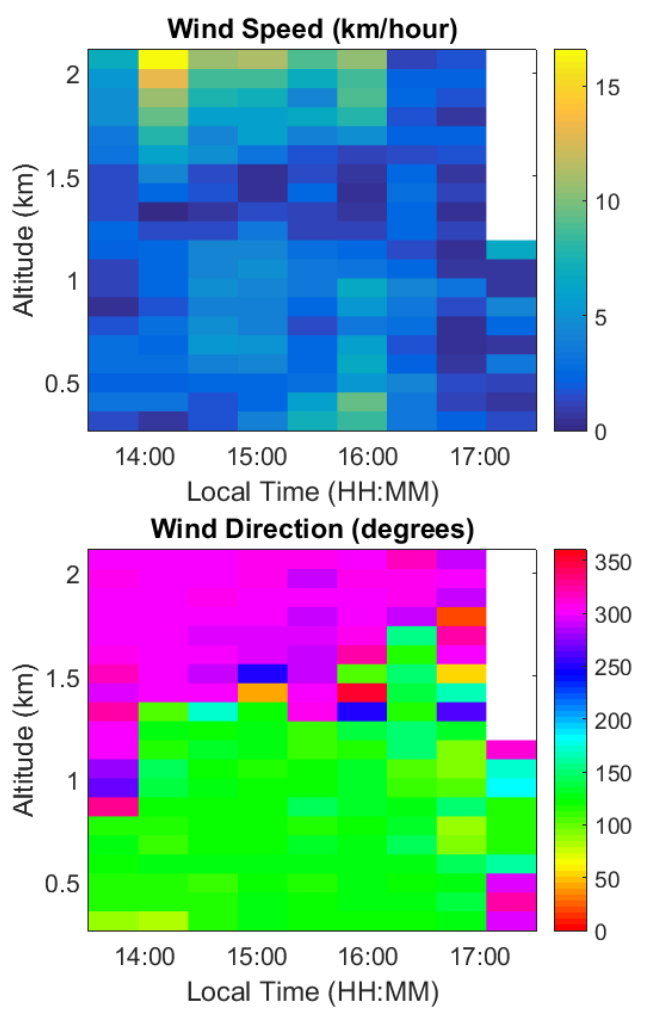

Figure 4 Wind speed and direction measurements from radar wind profiler.

The data from the three different stations consistently show winds originating from the south (around $180^{\circ}$ ) with speeds between 4 and $10 \mathrm{~km} /$ hour. Moreover, measurements from the wind profiler indicate that the southerly winds extend up to $1.4 \mathrm{~km}$ height. This confirms that the lower aerosol layer observed on the scanning measurements is indeed being transported from south to north.

The increase in the amount of aerosols throughout the day, and the appearance of the aerosol layers were also observed on simultaneous measurements taken with a colocated Vaisala CL 51 ceilometer (figure 6).
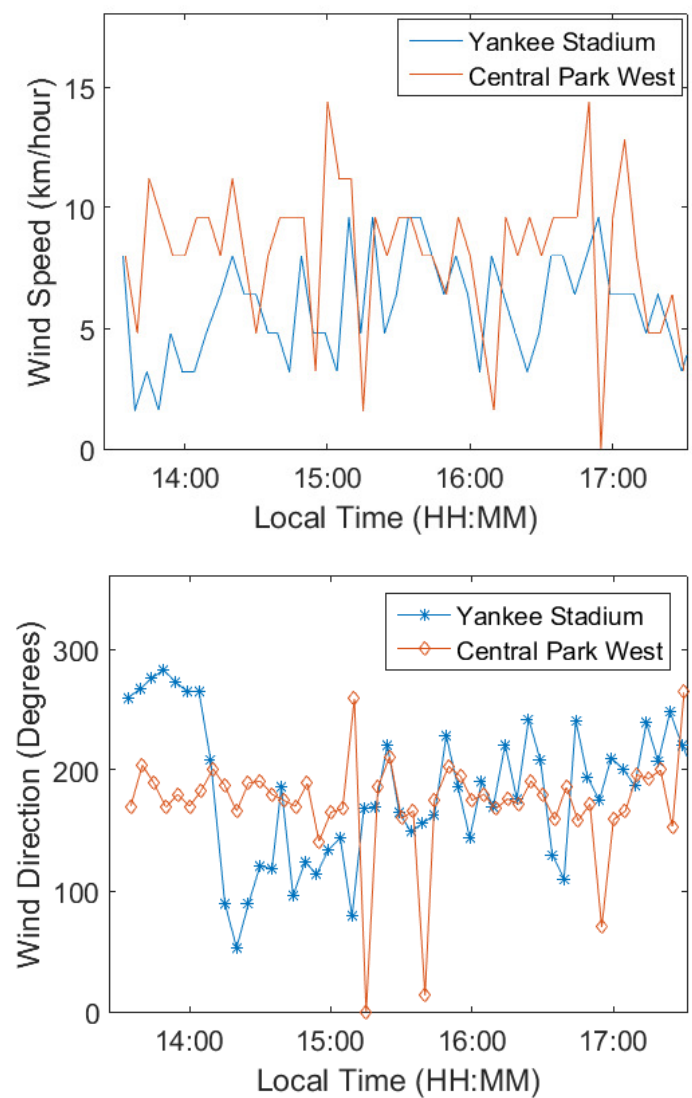

Figure 5 Wind speed and direction measurements from weather stations at Yankee Stadium and Central Park West.

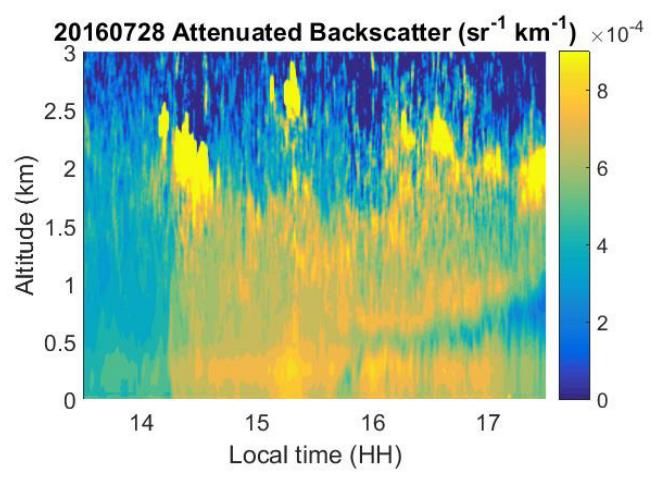

Figure 6 Simultaneous ceilometer measurements.

On July $20^{\text {th }}$, measurements were taken using the MPL fixed at $90^{\circ}$ elevation with 30 meters resolution and 1 minute averages from 11 to 15:30 local time. Measurements using the $532 \mathrm{~nm}$ channel of a co-located multi-wavelength lidar were taken during the same period of time for comparison purposes. It can be observed that both measurements are consistent and show fairly similar distributions (figure 7). 

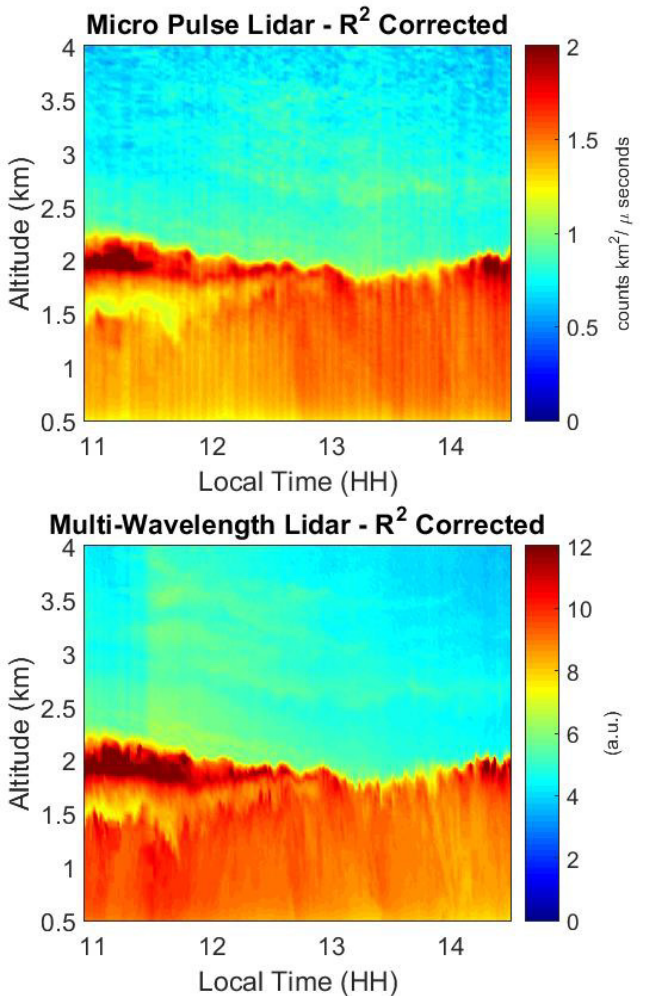

Figure 7 Measurements from (Top) MPL and (Bottom) multi-wavelength lidar.

\section{CONCLUSIONS}

Boundary layer dynamics in New York City have been observed by acquiring multi-dimensional distributions of aerosols with a scanning micro pulse lidar. Obtained measurements are supported by simultaneous PM 2.5 concentration measurements and the use of a ceilometer. Simultaneous wind speed and direction measurements were used to better understand dynamics and evolution of aerosol distribution. Additionally, measurements from this instrument are in agreement with the ones obtained with a co-located multi-wavelength lidar. In future studies, the effects of changes that might occur during the duration of a scan will be taken into account.

\section{ACKNOWLEDGEMENTS}

This study was supported by National Oceanic and Atmospheric Administration (NOAA) under Grant \#NA11SEC4810004 and by New York State Energy Research and Development Authority (NYSERDA).

\section{References}

[1] Behrendt, A., Pal, S., Wulfmeyer, V. and Lammel, G., 2011. A novel approach for the characterization of transport and optical properties of aerosol particles near sourcesPart I: Measurement of particle backscatter coefficient maps with a scanning UV lidar. Atmospheric environment, 45(16), pp.27952802.

[2] Späth, F., Behrendt, A., Muppa, S.K., Metzendorf, S., Riede, A. and Wulfmeyer, V., 2016. 3-D water vapor field in the atmospheric boundary layer observed with scanning differential absorption lidar. Atmospheric Measurement Techniques, 9(4), pp.1701-1720.

[3] De Wekker, S.F. and Mayor, S.D., 2009. Observations of atmospheric structure and dynamics in the Owens Valley of California with a ground-based, eye-safe, scanning aerosol lidar. Journal of Applied Meteorology and Climatology, 48(7), pp.1483-1499.

[4] Mayor, S.D., Spuler, S.M., Morley, B.M. and Loew, E., 2007. Polarization lidar at $1.54 \mu \mathrm{m}$ and observations of plumes from aerosol generators. Optical Engineering, 46(9), pp.096201-096201.

[5] American National Standards Institute, Z136.6, 2015. American National Standard for Safe Use of Lasers Outdoors, American National Standards Institute, New York.

[6] Spinhirne, J.D., 1993. Micro pulse lidar. IEEE Transactions on Geoscience and Remote Sensing, 31(1), pp.48-55.

[7] Welton, E.J., Campbell, J.R., Spinhirne, J.D. and Scott III, V.S., 2001, February. Global monitoring of clouds and aerosols using a network of micropulse lidar systems. In Second International Asia-Pacific Symposium on Remote Sensing of the Atmosphere, Environment, and Space (pp. 151-158). International Society for Optics and Photonics. 